Acetate: $\mathrm{mp} 80^{\circ}$; Found: $\mathrm{C}, 54.31 ; \mathrm{H}, 5.15 ; \mathrm{C}_{32} \mathrm{H}_{36} \mathrm{O}_{18}$ requires $\mathrm{C}$, 54.2; H, 5.15; ${ }^{1} \mathrm{H}$ NMR $\left(\mathrm{CDCl}_{3}\right): \delta 6.26(1 \mathrm{H}, d, J=10 \mathrm{~Hz}, \mathrm{H}-3)$, $7.65(1 \mathrm{H}, d, J=10 \mathrm{~Hz}, \mathrm{H}-4), 7.40(1 \mathrm{H}, d, J=9 \mathrm{~Hz}, \mathrm{H}-5), 6.90$ $(1 \mathrm{H}, d d, J=9$ and $2 \mathrm{~Hz}, \mathrm{H}-6), 6.90(1 \mathrm{H}, d, J=2 \mathrm{~Hz}, \mathrm{H}-8)$, coumarin protons $5.2(4 \mathrm{H}, m), 4.92(1 \mathrm{H}, s), 4.64(1 \mathrm{H}, q, J=12$, $6 \mathrm{~Hz}), 4.13(2 \mathrm{H}, d, J=1.8 \mathrm{~Hz})$; sugar protons and acetoxyl chemical shifts given in the text.

Acknowledgements - Our thanks are due to Prof. J. Shoji, School of Pharmaceutical Sciences, Showa University, Halanodal, Shinagawa-Ku, Tokyo 142, Japan, for a sample of apin. One of us (PSM) gratefully acknowledges the CSIR for the award of a senior research fellowship.

\section{REFERENCES}

1. Nair, A. G. R. and Subramanian, S. S. (1975) Phytochemistry $14,1135$.

2. Anjaneyulu, A. S. R., Rao, K. J., Rao, V. K., Row, L. R., Subrahmanian, C., Pelter, A. and Ward, R. S. (1975) Tetrahedron 31, 1277.

3. Anjaneyulu, A.S. R., Rao, A. M., Rao, V.K., Row, L. R., Pelter, A. and Ward, R. S. (1977) Tetrahedron 33, 133.

4. Markham, K. R., Ternai, B., Stanley, R., Geigler, H. and Mabry, J. J. (1978) Tetrahedron 34, 1389.

5. Austın, D. J. and Meyers, M. B. (1965) Phytochemistry 4, 255.

6. Sakuma, S. and Shoji, J. (1981) Chem. Pharm Bull. 29, 2431.

\title{
(+)-CALOCEDRIN, A LIGNAN DIHYDROANHYDRIDE FROM CALOCEDRUS FORMOSANA
}

\author{
Jim-Min Fang, Shyi-Tai Jan and Yu-Shia Cheng \\ Department of Chemıstry, National Taiwan Universıty, Taipei, Taiwan, Republıc of Chına
}

(Revised received 28 November 1984)

Key Word Index-Calocedrus formosana; Cupressaceae; calocedrın; lignan dihydroanhydride; hibalactone.

\begin{abstract}
A novel lignan dihydroanhydride, $(+)$-calocedrin, was isolated from the wood of Calocedrus formosana. Its structure was determined to be trans- $\alpha$-(3,4-methylenedioxybenzylidene)- $\beta$ - (3,4-methylenedioxybenzyl)- $\gamma$-hydroxybutanolide by spectroscopic methods. Reduction of $(+)$-calocedrin resulted in an optically inactive lignan lactone, ( \pm )-hibalactone.
\end{abstract}

\section{INTRODUCTION}

Calocedrus formosana, a member of the Cupressaceac, is an economically important tree indigenous to Taiwan [1]. Previous investigations $[2,3]$ on the heartwood have shown that it contains essential oil and a large quantity of terpenoid acids, such as shonanic, thujic and chaminic. Lignan components, such as hinokinin and hibalactone (savinin), have also been found.

\section{RESULTS AND DISCUSSION}

On continuing a study of the chemical constituents, the wood of $C$. formosana was collected in our campus and subjected to extraction with acetone. The combined extracts were concentrated and the residual contents separated on a silica gel column eluting with hexane-ethyl acetate gradients. After (-)-hibalactone $1\left(R_{f} 0.30\right.$, hexane-acetone, $7: 3)[4,5]$, a novel lignan, namely $(+)$ calocedrin, was eluted $\left(R_{f}, 0.16\right)$. Calocedrin was recrystallized from ethanol, $\mathrm{mp} 187-188^{\circ},[\alpha]_{\mathrm{D}}^{25}+6^{\circ}(\mathrm{c} 0.9$; acetone). The mass spectrum displayed the parent peak at

$m / z 368$ and the base peak at $m / z 135$, ascribable to the 3,4 methylenedioxybenzyl fragment. The IR spectrum showed the presence of hydroxyl $\left(3560 \mathrm{~cm}^{-1}\right)$, lactone $\left(1745 \mathrm{~cm}^{-1}\right)$ and olefin $\left(1640 \mathrm{~cm}^{-1}\right)$ groups. Analyses of

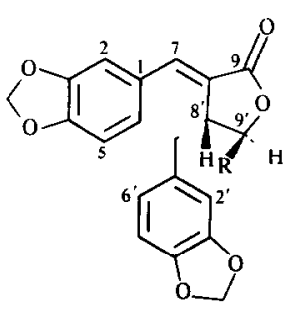

$1 \mathbf{R}=\mathbf{H}$

$2 \mathrm{R}=\mathrm{OH}$<smiles>[2H][C@H](Cc1ccc2c(c1)OCO2)[C@@H](C=O)/C(=C\c1ccc2c(c1)OCO2)C(=O)O[NH3+]</smiles>

3 
the ${ }^{1} \mathrm{H}$ and ${ }^{13} \mathrm{C}$ NMR spectra (Tables 1 and 2 ) revealed that the structure of $(+)$-calocedrin (2) was related to that of hibalactone. Calocedrin contained an unusual hemiacetal lactone $\left(-\mathrm{CO}_{2}-\mathrm{CHOH}-\right)$ moiety as characterized in the ${ }^{1} \mathrm{H}$ NMR spectrum [6]. The hydroxyl proton, coupled by $\mathrm{H}-9^{\prime}$, exhibited as a doublet $(J=5.5 \mathrm{~Hz})$ at $\delta 6.49$ that was shifted by change of concentration or temperature. Similarly, the hemiacetal proton (H-9') was coupled by the hydroxyl proton, displaying as a doublet $(J=5.5 \mathrm{~Hz})$ at $\delta 5.67$. Since irradiation at the resonance of $H-8^{\prime}(\delta 3.71)$ did not cause any apparent effect on the signal pattern of $H-9^{\prime}$, these two protons should orient nearly orthogonally (trans configuration) according to the Karplus empirical rule.

The structures of calocedrin and hibalactone are chemi-

Table 1. ${ }^{1} \mathrm{H}$ NMR spectral data of (-)-hibalactone 1 and (+)-calocedrin $2\left(\mathrm{Me}_{2} \mathrm{CO}-d_{6}, 90 \mathrm{MHz}, \mathrm{TMS}, \delta\right)$

\begin{tabular}{lll}
\hline & \multicolumn{1}{c}{1} & \multicolumn{1}{c}{2} \\
\hline $\mathrm{H}-7$ & $7.49(d, 1.5)^{*}$ & $7.43(d, 1.5)$ \\
$\mathrm{H}-7^{\prime}$ & $2.56(d d, 15,10)$, & $2.65(d d, 15,10)$, \\
& \multicolumn{1}{c}{$3.00(d d, 15,5)$} & \multicolumn{1}{c}{$2.94(d d, 15,5)$} \\
$\mathrm{H}-8^{\prime}$ & $3.75(m)$ & $3.71(d d d, 10,5,1.5)$ \\
$\mathrm{H}-9^{\prime}$ & $4.25(d, 5)$ & $5.67(d, 5.5)$ \\
OCH ${ }_{2} \mathrm{O}$ & $5.92(s), 6.02(s)$ & $5.93(s), 6.07(s)$ \\
OH & & $6.49(d, 5.5)$ \\
Aromatic & $6.60-7.14(m)$ & $6.75-7.29(m)$ \\
\hline
\end{tabular}
(Hz).

* Numbers in parentheses indicate coupling constants

Table $2 .{ }^{13} \mathrm{C}$ NMR spectral data of (-)-hibalactone 1 and $(+)$ calocedrin $2\left(\mathrm{Me}_{2} \mathrm{CO}-\mathrm{d}_{6}, 25.2 \mathrm{MHz}, \delta\right)$

\begin{tabular}{lccccc}
\hline C & 1 & 2 & C & 1 & 2 \\
\hline 1 & $129.2(s)$ & $128.8(s)$ & $1^{\prime}$ & $132.7(s)$ & $132.2(s)$ \\
2 & $108.8(d)$ & $108.7(d)$ & $2^{\prime}$ & $109.3(d)$ & $109.2(d)$ \\
3 & $149.7(s)$ & $149.7(s)$ & $3^{\prime}$ & $149.1(s)$ & $148.9(s)$ \\
4 & $148.6(s)$ & $148.4(s)$ & $4^{\prime}$ & $146.9(s)$ & $146.7(s)$ \\
5 & $110.0(d)$ & $109.8(d)$ & $5^{\prime}$ & $109.5(d)$ & $109.4(d)$ \\
6 & $122.9(d)$ & $122.7(d)$ & $6^{\prime}$ & $126.3(d)$ & $126.3(d)$ \\
7 & $136.7(d)$ & $137.4(d)$ & $7^{\prime}$ & $38.2(t)$ & $36.2(t)$ \\
8 & $127.8(s)$ & $126.9(s)$ & $8^{\prime}$ & $40.1(d)$ & $48.2(d)$ \\
9 & $172.0(s)$ & $171.3(s)$ & $9^{\prime}$ & $70.1(t)$ & $99.8(d)$ \\
$\mathrm{OCH}_{2} \mathrm{O}$ & $101.7(t)$, & $101.6(t)$, & & & \\
\multicolumn{5}{c}{$102.6(t)$} & $102.5(t)$ \\
\hline
\end{tabular}

cally correlated. (+)-Calocedrin was reduced by sodium borohydride in the presence of sodium hydroxide [7]. The product (66\% yield) exhibited compatible physical and spectroscopic properties (mp, mmp, HPLC, UV, IR and ${ }^{1}$ H NMR) with those of (-)-hibalactone, except optical activity. An intermediate aldehyde 3, obtained from hemiacetal opening, was presumed to undergo epimerization prior to reduction under the alkaline conditions.

\section{EXPERIMENTAL}

Plant material. Calocedrus formosana (Florin) Florin was collected in the campus of the National Taiwan University. The skinned and air-dried wood $(600 \mathrm{~g})$ from branches $6-8 \mathrm{~cm}$ in diam. was selected for study After extraction $\times 3$ with $\mathrm{Me}_{2} \mathrm{CO}$, the combined extracts were concd in vacuo to give $20 \mathrm{~g}$ of residue. Components were separated by $\mathrm{CC}$ on silica gel $(230 \mathrm{~g})$ and elution with hexane-EtOAc gradients.

$(+)$-Calocedrin. Crystals $(105 \mathrm{mg}) \boldsymbol{R}_{f} \mathbf{0 . 1 6}$ (hexane- $\mathrm{Me}_{2} \mathrm{CO}$, 7:3). Recrystallization samples from EtOH exhibited $\mathrm{mp}$ 187-188; $[\alpha]_{\mathrm{D}}^{25}+6^{\circ}$ (c 0.9; $\left.\mathrm{Me}_{2} \mathrm{CO}\right)$. UV $\lambda \lambda_{\max }^{\mathrm{E} O H} \mathrm{~nm}(\varepsilon): 237$ (10400), 294 (9560), 330 (11 600). IR $v_{\text {mar }}^{\mathrm{KBr}} \mathrm{cm}^{-1}: 3560$ (OH), 1745 $(\mathrm{C}=\mathrm{O}), 1640(\mathrm{C}=\mathrm{C}), 1600$ (aromatic). MS m/z (rel. int.): 368 (15) $[\mathrm{M}]^{+}, 350(9), 316(10), 135(100)$.

Reduction of (+)-calocedrin. $\mathrm{NaOH}(21 \mathrm{mg}, 0.53 \mathrm{mmol})$ was added to a soln of (+)-alocedrin ( $49 \mathrm{mg}, 0.13 \mathrm{mmol}$ ) in $\mathrm{MeOH}$. After stirring for $10 \mathrm{~mm}, \mathrm{NaBH}_{4}(6.5 \mathrm{mg}, 0.17 \mathrm{mmol})$ was added and the mixture refluxed $\left(80^{\circ}\right)$ for $1 \mathrm{hr}$ under $\mathrm{N}_{2}$. The mixture was cooled, acidified ( $\mathrm{pH}$ 2) with $\mathrm{HCl}$ and extracted with $\mathrm{CHCl}_{3}$. The combined extracts were dried over $\mathrm{Na}_{2} \mathrm{SO}_{4}$, filtered, concd and purified by $\mathrm{TLC}\left(\boldsymbol{R}_{f} 0.30\right.$, hexane- $\left.\mathrm{Me}_{2} \mathrm{CO}, 7: 3\right)$ to afford a $66 \%$ y1eld of ( \pm )-hibalactone ( $30 \mathrm{mg}, 0.085 \mathrm{mmol}$ ); $\mathrm{mp} 141.5-143^{\circ}$ (authentic (-)-hibalactone, $142-143^{\circ}$, lit. [5] $147^{\circ}$ ), mmp $139-142^{\circ}$. The synthetic and authentic samples had the same $R_{t}$ on HPLC ( $\mu$-Porasil column). UV $\lambda$ EtOH $\mathrm{nm}(\varepsilon): 237$ (12 100), 294 (10800), 332 (14140). IR $v_{\max }^{\mathrm{KBr}} \mathrm{cm}^{-1}: 1740,1640,1601 . \mathrm{MS} \mathrm{m} / \mathrm{z}$ (rel. int.): 352 (12) [M] ${ }^{+}, 217$ (18), 135 (100).

Acknowledgement-The authors thank the National Science Council (ROC) for financial support.

\section{REFERENCES}

1. Flora of Taiwan (1975) Vol. 1, p. 538. Epoch, Talwan.

2. Cheng, Y. S. and Lin, K. C. (1970) Chemistry (Chinese) 28.

3. Cheng, Y. S. and Lin, K. C. (1971) Chemistry (Chinese) 94.

4. Schrecker, A. W and Hartwell, J. L. (1954) J. Am. Chem. Soc. 76, 4896.

5. Batterbee, J. E., Burden, R. S., Crombie, L. and Whiting, D. A. (1969) J. Chem. Soc. C 2470.

6. Moss, M. O., Robinson, F. V. and Wood, A. B. (1971) J.Chem. Soc. C 619.

7 Ferland, J M., Lefebvre, Y., Deghenghi, R. and Wiesner, K. (1966) Tetrahedron Letters 3617 